\title{
ECONOMIC FEASIBILITY OF CARBON SEQUESTRATION WITH ENHANCED GAS RECOVERY (CSEGR)
}

\author{
C.M. Oldenburg ${ }^{1 *}$, S.H. Stevens ${ }^{2}$, S.M. Benson ${ }^{1}$ \\ ${ }^{1}$ Earth Sciences Division 90-1116, Lawrence Berkeley National Laboratory \\ Berkeley, CA 94720 USA \\ ${ }^{2}$ Advanced Resources International, Inc. \\ 4501 Fairfax Drive, Suite 910 \\ Arlington, VA 22203-1661 USA \\ *Corresponding author. $\quad$ Cmoldenburg@lbl.gov, fax: (510) 486-5686; phone: (510) 486-7419 \\ smbenson@lbl.gov, fax: (510) 486-6498; phone: (510) 486-5875 \\ sstevens@adv-res.com, fax: (703) 528-0439; phone: (703) 528-8420
}

\begin{abstract}
Prior reservoir simulation and laboratory studies have suggested that injecting carbon dioxide into mature natural gas reservoirs for carbon sequestration with enhanced gas recovery (CSEGR) is technically feasible. Reservoir simulations show that the high density of carbon dioxide can be exploited to favor displacement of methane with limited gas mixing by injecting carbon dioxide in low regions of a reservoir while producing from higher regions in the reservoir. Economic sensitivity analysis of a prototypical CSEGR application at a large depleting gas field in California shows that the largest expense will be for carbon dioxide capture, purification, compression, and transport to the field. Other incremental costs for CSEGR include: (1) new or reconditioned wells for carbon dioxide injection, methane production, and monitoring; (2) carbon dioxide distribution within the field; and, (3) separation facilities to handle eventual carbon dioxide contamination of the methane. Economic feasibility is most sensitive to wellhead methane price, carbon dioxide supply costs, and the ratio of carbon dioxide injected to incremental methane produced. Our analysis suggests that CSEGR may be
\end{abstract}


economically feasible at carbon dioxide supply costs of up to $\$ 4$ to $\$ 12 / \mathrm{t}$ ( $\$ 0.20$ to $\$ 0.63 / \mathrm{Mcf}$ ).

Although this analysis is based on a particular gas field, the approach is general and can be applied to other gas fields. This economic analysis, along with reservoir simulation and laboratory studies that suggest the technical feasibility of CSEGR, demonstrates that CSEGR can be feasible and that a field pilot study of the process should be undertaken to test the concept further.

\section{INTRODUCTION}

Carbon dioxide $\left(\mathrm{CO}_{2}\right)$ injection into oil reservoirs for enhanced oil recovery (EOR) has been a proven technical and economic success for more than 20 years. Although the advanced technology of injecting carbon dioxide $\left(\mathrm{CO}_{2}\right)$ into mature natural gas (methane, $\left.\mathrm{CH}_{4}\right)$ reservoirs for carbon sequestration with enhanced gas recovery (CSEGR) appears promising, it has not yet been tried in the field nor shown to be commercially feasible. The process of CSEGR is depicted in Figure 1 where we show the separation and compression of $\mathrm{CO}_{2}$ from industrial and petroleum refining sources, injection into a mature natural gas reservoir, repressurization and enhanced production of $\mathrm{CH}_{4}$, and the beneficial use of the $\mathrm{CH}_{4}$ as a fuel. The mechanism of CSEGR is gas displacement and pressurization, as injected $\mathrm{CO}_{2}$ moves through the pore space displacing $\mathrm{CH}_{4}$ ahead of it [1]. This is in contrast to EOR which relies on miscibility of $\mathrm{CO}_{2}$ with the oil phase, and enhanced recovery facilitated by the density and viscosity decrease of the oil- $\mathrm{CO}_{2}$ mixture and corresponding greater mobility in the reservoir.

From the point of view of geologic carbon sequestration, depleted natural gas reservoirs are a promising target given their proven history of gas containment and production. The ultimate worldwide storage capacity of depleted natural gas reservoirs has been estimated at $800 \mathrm{Gt}_{2}(8 \mathrm{x}$ 
$10^{14} \mathrm{~kg} \mathrm{CO}_{2}$ ) [2]. As for enhanced gas recovery, the average worldwide gas recovery factor is estimated to be approximately $75 \%$ [3], with roughly $30-40 \%$ of the gas in place left behind in waterdrive gas reservoirs and approximately 10-20\% left behind in depletion-drive reservoirs. Even 10\% of the original gas in place in a depletion-drive reservoir can represent a large volume of currently unrecovered gas that makes potential incremental $\mathrm{CH}_{4}$ production attractive when the alternative is field abandonment. In water-drive reservoirs where the potential additional $\mathrm{CH}_{4}$ recovery potential is much higher, $\mathrm{CO}_{2}$ injection will maintain reservoir pressure that will tend to keep water out of the reservoir. If $\mathrm{CO}_{2}$ breakthrough to production wells occurs, separation of $\mathrm{CO}_{2}$ from $\mathrm{CH}_{4}$ can be carried out as a gas processing step with reinjection of the captured $\mathrm{CO}_{2}$. Based on reservoir simulation and experimental studies, the process of CSEGR appears to be technically feasible. In particular, we have carried out numerical simulations of $\mathrm{CO}_{2}$ injection into model natural gas reservoirs to study the processes of reservoir pressurization, gas displacement, and gas mixing [1,4]. Independent laboratory experiments of the displacement of $\mathrm{CH}_{4}$ by supercritical $\mathrm{CO}_{2}$ have further demonstrated the promise of CSEGR [5].

The purpose of this study is to investigate the economic feasibility of CSEGR. We selected the Rio Vista Gas Field in the Sacramento-San Joaquin Delta area of California (USA) for analysis. This gas field is typical of large onshore mature gas fields not associated with oil, and has the added feature of being near potentially large sources of $\mathrm{CO}_{2}$ in the San Francisco Bay area. In our analysis, we first estimated the capital costs and operating costs for $\mathrm{CO}_{2}$ acquisition and distribution, drilling or recompleting $\mathrm{CO}_{2}$ injection and $\mathrm{CH}_{4}$ production wells, gas purification and compression, and field design and monitoring. These costs are offset by the production of additional $\mathrm{CH}_{4}$, the price of which will be variable depending on future market conditions. Although focused on a mature reservoir in 
California, the approach is general and can be used at other gas fields with appropriate changes in model variables. We focus our analysis on the present-day circumstances in which $\mathrm{CO}_{2}$ must be bought from a supplier and is therefore a significant cost of CSEGR. Before presenting the economic analysis, we show reservoir simulation results of the physical process of CSEGR for the Rio Vista scenario being considered.

\section{RESERVOIR SIMULATION}

A simplified numerical model based on the Rio Vista system [6] was developed for demonstrating the physical process of CSEGR. The reservoir is assumed to consist of $25 \mathrm{CO}_{2}$ injection wells, $16 \mathrm{CH}_{4}$ production wells, and 8 monitoring wells placed over the central part of the $16 \mathrm{~km}$ long by $7 \mathrm{~km}$ wide Rio Vista gas field. The well pattern and quarter five spot domain for simulation are shown schematically in Figure 2. Injection and production are assumed to be in the Domengine sandstone, the largest gas pool at Rio Vista. Note in Figure $2 b$ that the CSEGR strategy we demonstrate involves injection of $\mathrm{CO}_{2}$ into the lower regions of the thick reservoir while producing $\mathrm{CH}_{4}$ from the upper regions. Injection of $\mathrm{CO}_{2}$ is at a constant rate of 2.4 million $\mathrm{t} /$ year over the whole field, and uniformly distributed between the 25 injection wells ( $260 \mathrm{t} /$ day per well). For comparison, this rate is approximately $57 \%$ of the $\mathrm{CO}_{2}$ production rate of the nearby $680 \mathrm{MW}$ gas-fired powerplant at Antioch, California. The simulation incorporates a total $\mathrm{CH}_{4}$ production rate fixed at $750 \mathrm{t} / \mathrm{year}(150$ MMMcf), or $48 \mathrm{t} /$ day per well. This high production rate is nearly equal to the peak Rio Vista

production in the 1940s, and was chosen simply to demonstrate CSEGR with a significant 
enhancement in production over the current Rio Vista production which is approximately $10^{7} \mathrm{Mcf} / \mathrm{yr}$. Current production at Rio Vista represents the flattening tail of a production curve that declined by nearly one half from 1950 to 1960 , and declined by over half again from 1960 to 1990 . The idealized scenario simulated here allows approximately seven times more gas to be produced from the reservoir over 15 years than the current production projected over this same period [1]. Other properties of the model reservoir are presented in Table 1. Simulations are carried out using a new module for TOUGH2 [7] called EOS7C. This simulator calculates real-gas mixture properties in the ternary system $\mathrm{H}_{2} \mathrm{O}-\mathrm{CO}_{2}-\mathrm{CH}_{4}$ and models flow and transport of supercritical $\mathrm{CO}_{2}, \mathrm{CH}_{4}$, and water in gas and aqueous phases in three-dimensional model reservoirs.

We present in Figure 3 simulation results for the gas composition and density after 15 years of injection and production. Note that injecting $\mathrm{CO}_{2}$ into the lower part of the reservoir while producing gas from the upper part of the reservoir exploits the large density contrast between $\mathrm{CO}_{2}$ and $\mathrm{CH}_{4}$ to delay $\mathrm{CO}_{2}$ breakthrough and effectively fill the reservoir from the bottom up. To summarize the large number of process simulations we have carried out over the last few years, we can say that (1) the high density and viscosity of $\mathrm{CO}_{2}$ favor CSEGR by limiting gas mixing, (2) that reservoir heterogeneity tends to accelerate breakthrough of $\mathrm{CO}_{2}$ to production wells, but (3) that repressurization of the reservoir occurs faster than $\mathrm{CO}_{2}$ breakthrough. An optimal strategy is to take advantage of the higher density of $\mathrm{CO}_{2}$ and inject it into the lower portions of the reservoir to drive out the remaining lighter $\mathrm{CH}_{4}$, while minimizing mixing and contamination in the upper parts of the reservoir. Our simulations suggest that CSEGR is feasible from a process perspective in that the injection of $\mathrm{CO}_{2}$ into depleted gas reservoirs can enhance $\mathrm{CH}_{4}$ recovery, while simultaneously 
sequestering large amounts of $\mathrm{CO}_{2}$. In the following section, we analyze the economic feasibility of this particular CSEGR scenario.

\section{ECONOMIC FEASIBILITY ANALYSIS}

The economic feasibility of CSEGR depends on the incremental benefits of gas recovery relative to the incremental expenses of CSEGR. A key decision for evaluating CSEGR applications -- as well as for $\mathrm{CO}_{2}$-enhanced oil recovery and coalbed methane projects - is proper timing: At what stage is $\mathrm{CO}_{2}$ injection optimal? CSEGR technology may be applied at any stage in the life of a natural gas field, from initial discovery and development all the way to depletion and field abandonment. We believe that the optimal application of CSEGR is in mature (but not abandoned) natural gas fields where production is declining. We refer to such mature reservoirs that are still in production but that are becoming depleted as "depleting" reservoirs and focus our analysis on applying CSEGR at this stage in the life of the reservoir. A depleting gas field already has in place a working infrastructure of producing wells, gas gathering, treatment, compression, and transport facilities, plus the necessary regulatory approvals. In contrast, newly discovered fields lack infrastructure and their reservoir behavior is still poorly understood, making $\mathrm{CO}_{2}$ injection more risky. Likewise, abandoned fields face large rehabilitation costs as well as regulatory hurdles. Our economic model assumes that CSEGR is applied to a depleting gas field, such as the Rio Vista field in the Sacramento Valley, the largest onshore gas field in California [6], estimated to contain an additional $3 \mathrm{Tcf}$ of recoverable gas [8].

Incremental capital costs for CSEGR include $\mathrm{CO}_{2}$ acquisition and transport via pipeline to the field, distribution of $\mathrm{CO}_{2}$ within the field, injection wells, monitoring systems, $\mathrm{CH}_{4}$ compression and 
(eventually) $\mathrm{CH}_{4} / \mathrm{CO}_{2}$ separation facilities. A major expense today is the cost of acquiring $\mathrm{CO}_{2}$, which may range from $\$ 10 /$ from a relatively pure fertilizer or cement plant source up to $\$ 50 / t$ for a retrofitted power plant. We assumed that $\mathrm{CO}_{2}$ is supplied at high purity and pressure to the pipeline terminus. We computed the maximum price that the field operator could afford to pay for $\mathrm{CO}_{2}$ supply to break even under a $15 \%$ rate of return (pre-income taxes), under varying wellhead gas price and $\mathrm{CO}_{2} / \mathrm{CH}_{4}$ ratios. We assumed that the field operator would construct a new $50-\mathrm{km}$ long pipeline and pipeline distribution network to transport $\mathrm{CO}_{2}$ from the supply source to wells throughout the field. We assumed that existing shut-in or abandoned wells could be converted to dedicated $\mathrm{CO}_{2}$ injection or monitoring wells at a cost of approximately one-third that of drilling new wells. Eventually, injected $\mathrm{CO}_{2}$ mixes with $\mathrm{CH}_{4}$ within the reservoir, requiring costly gas separation and conversion of the wellhead and flow lines to corrosion-resistant materials.

We estimated capital and operating costs for the CSEGR application based on current California gas production operations and experience at natural $\mathrm{CO}_{2}$ production fields and EOR operations. The economic analysis is carried out with the same assumptions as the reservoir simulation presented above, with development and cost assumptions summarized in Tables 2 and 3. Standard royalty, severance, and other production taxes were subtracted from the cash flow.

While most of the variables in the model are generalized economic variables, some depend on the physical processes of CSEGR and can be estimated from reservoir simulation results. For example, the volumetric ratio of injected $\mathrm{CO}_{2}$ to incrementally produced $\mathrm{CH}_{4}$ depends on processes in the reservoir. Physically, this ratio represents the efficiency of EGR in terms of the displacement of $\mathrm{CH}_{4}$ by $\mathrm{CO}_{2}$; the closer the ratio is to unity, the more efficient is the gas recovery process. The degree to 
which this ratio is greater than unity can reflect the combined effects of repressurization of the reservoir, dissolution of $\mathrm{CO}_{2}$ into connate water, gas mixing, and reservoir geometry. Briefly, the $\mathrm{CO}_{2}$ is denser than $\mathrm{CH}_{4}$ and the change in density of $\mathrm{CO}_{2}$ as pressure increases through the critical pressure of 73.8 bars is much larger than the change in density of $\mathrm{CH}_{4}$ at typical reservoir temperatures. The result of this difference is that it takes more $\mathrm{CO}_{2}$ to displace a given volume of $\mathrm{CH}_{4}$ in a high-pressure reservoir. However, because deeper reservoirs tend to be at higher temperatures, the effects of higher pressure on $\mathrm{CO}_{2}$ density are moderated. Furthermore, while repressurization and dissolution tend to make the ratio larger than unity, gas mixing decreases the ratio because the density of supercritical $\mathrm{CO}_{2}$ decreases drastically upon mixing with small amounts of $\mathrm{CH}_{4}$ which causes pressure increases with no additional injection whatsoever (e.g., [4]).

To capture expected variability in volume ratio, we tested the sensitivity of the result using volume ratio values of $1.5,2.0$, and 3.0 by varying the assumed incremental $\mathrm{CH}_{4}$ production under a constant $\mathrm{CO}_{2}$ injection rate. For reference, the volumetric ratio for the idealized case simulated above was approximately 2.0. Another physical property that can be estimated from simulation results is the gas composition, or mass fraction $\mathrm{CH}_{4}$ in the produced gas. This property starts at unity in CSEGR, but declines as mixing occurs in the reservoir and $\mathrm{CO}_{2}$ breaks through to the production wells. At 15 years in the scenario simulated above, the $\mathrm{CH}_{4}$ mass fraction in the gas at the production well is approximately 0.80 . For the purposes of the economic analysis presented here, we will assume that EGR is stopped (reservoir shut in) if the mass fraction of $\mathrm{CH}_{4}$ drops below 0.5 at the production well. Carbon sequestration by $\mathrm{CO}_{2}$ injection can continue for decades after the reservoir is shut in [1]. Following CSEGR, the $\mathrm{CO}_{2}$-filled reservoir can be used for gas storage with $\mathrm{CO}_{2}$ serving as a very 
effective cushion gas because of its large effective compressibility around its critical pressure and temperature [9].

\section{RESULTS}

The economic analysis shows that CSEGR may be economically feasible if the supply cost of $\mathrm{CO}_{2}$ is low, if $\mathrm{CO}_{2} / \mathrm{CH}_{4}$ mixing is slow so there is little $\mathrm{CO}_{2}$ breakthrough, and if there is a significant amount of $\mathrm{CH}_{4}$ remaining in the reservoir to be recovered. Sensitivity analysis using the CSEGR economic model shows that the most critical parameters are wellhead natural gas price and the ratio of $\mathrm{CO}_{2}$ injected to incremental $\mathrm{CH}_{4}$ produced. The risk of natural gas price drop may be hedged, while capital costs may be estimated with reasonable certainty. Thus, the major remaining unknown economic factors are the volumetric $\mathrm{CO}_{2} / \mathrm{CH}_{4}$ ratio and the time to breakthrough. These key factors are likely to vary from field to field, based on reservoir architecture and field operation strategies, and can be forecasted using detailed reservoir simulation. However, field testing of CSEGR is needed to demonstrate empirically its feasibility and to clarify the influence of key economic variables.

Figure 4 shows the results of the sensitivity analysis. The base case $\left(\mathrm{CO}_{2} / \mathrm{CH}_{4}=1.5\right.$ and wellhead $\mathrm{CH}_{4}$ price $=\$ 3.00 / \mathrm{MMBtu} \approx \$ 3.00 / \mathrm{Mcf}$ ) shows that CSEGR may be economic at $\mathrm{CO}_{2}$ supply costs of under $\$ 8 / \mathrm{t}(\$ 0.40 / \mathrm{Mcf})$. This breakeven threshold rises to over $\$ 15 / \mathrm{t}(\$ 0.79 / \mathrm{Mcf})$ at a $\$ 5 / \mathrm{Mcf}$ wellhead price. These $\mathrm{CO}_{2}$ prices are only slightly below actual current $\mathrm{CO}_{2}$ prices from geologic sources and low-cost gas processing plants in the Permian and Rocky Mountain basins of the western USA. However, capture, separation, and compression costs from power plants are far higher, perhaps $\$ 50 /$ t $(\$ 3.00 / \mathrm{Mcf})$. Under current technology, CSEGR would require a significant subsidy for $\mathrm{CO}_{2}$ sequestration to be economic using flue gas $\mathrm{CO}_{2}$ sources. 
Two other sensitivity cases were run with less optimistic assumptions, using $\mathrm{CO}_{2} / \mathrm{CH}_{4}$ ratios of 2.0 and 3.0 (Figure 3). These scenarios represent fields with greater reservoir hetereogeneity and/or less remaining $\mathrm{CH}_{4}$ in place. Breakeven $\mathrm{CO}_{2}$ supply costs for these less favorable reservoirs ranged from

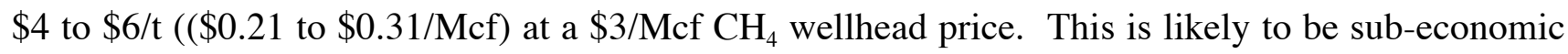
even using low-cost natural $\mathrm{CO}_{2}$ field sources, which do not exist in California. However, advances in CSEGR injection, production, and field management technologies could reduce $\mathrm{CO}_{2} / \mathrm{CH}_{4}$ ratios and improve CSEGR economics. Furthermore, if future $\mathrm{CO}_{2}$ markets involve effective payment for carbon sequestration, $\mathrm{CO}_{2}$ may be free to the operator or even become a potential revenue stream making CSEGR even more attractive economically.

\section{CONCLUSIONS}

CSEGR may be economically feasible provided the volumetric ratio of $\mathrm{CO}_{2}$ injected to incremental $\mathrm{CH}_{4}$ produced is less than about three, depending on $\mathrm{CO}_{2}$ supply costs and $\mathrm{CH}_{4}$ wellhead prices. Many uncertainties remain in the evaluation of a new recovery and sequestration process, among which are uncertain monitoring requirements and uncertain $\mathrm{CO}_{2}$ markets. For example, possible future $\mathrm{CO}_{2}$ markets may involve payment to operators willing to accept $\mathrm{CO}_{2}$ and inject it into the ground for carbon sequestration. In this case, $\mathrm{CO}_{2}$ is no longer a cost but rather a revenue and the economics of CSEGR will be considerably more favorable. In any case, CSEGR will have to be evaluated on a field-by-field basis considering reservoir properties and conditions. The analysis in this study was based on an idealized model reservoir assuming homogeneous permeability and a single gas-bearing layer. In addition, the economic model was based on simulation results of a lowpressure reservoir, i.e., highly depleted and below the critical pressure of $\mathrm{CO}_{2}$. For these reasons, the 
results of our study must be considered tentative and subject to revision as more detailed reservoir simulations are carried out. Nevertheless, our results suggest that CSEGR will be feasible under certain conditions. Because both reservoir simulation and laboratory studies have also suggested that CSEGR is technically feasible, it is now time to consider seriously the development of a field pilotstudy test of CSEGR.

\section{ACKNOWLEDGMENT}

We are grateful for the review comments of André Unger and Larry Myer (LBNL), and an anonymous reviewer. This work was supported in part by the Assistant Secretary for Fossil Energy, Office of Coal and Power Systems through the National Energy Technology Laboratory, and by Lawrence Berkeley National Laboratory under Department of Energy Contract No. DE-AC03$76 \mathrm{SF} 00098$.

\section{REFERENCES}

[1] Oldenburg CM, Pruess K, Benson SM. Process modeling of $\mathrm{CO}_{2}$ injection into natural gas reservoirs for carbon sequestration and enhanced gas recovery, Energy \& Fuels 2001;15:293-298.

[2] Stevens SH, Kuuskraa VK, and Gale J. "Sequestration of $\mathrm{CO}_{2}$ in Depleted Oil and Gas Fields: Global Capacity and Barriers to Overcome.” Fifth International Conference on Greenhouse Gas Control Technologies, Cairns, Australia, 13-16 August, 2000.

[3] Laherrere J. Distribution and evolution of "recovery factor", presented at IEA Oil Reserves Conference, Paris, France, Nov. 11, 1997. See also: http://dieoff.org/page183.pdf 
[4] Oldenburg CM, Benson SM. $\mathrm{CO}_{2}$ injection for enhanced gas production and carbon sequestration, Society of Petroleum Engineers SPE-74367, SPE International Petroleum Conference and Exhibition in Mexico, Villahermosa, Mexico, 10-12 Feb. 2002.

[5] Mamora DD, Seo JG, Enhanced gas production by carbon dioxide sequestration in depleted gas reservoirs, Society of Petroleum Engineers SPE-77347, SPE Annual Technical Conference and Exhibition, San Antonio, Texas, USA, 29 Sept.-2 Oct. 2002.

[6] Johnson DS. Rio Vista Field-USA, Sacramento basin, Calif., in Foster NH, Beaumont EA, eds., “Atlas of Oil and Gas Fields, Structural Traps III,” AAPG Treatise of Petroleum Geology, Atlas of Oil and Gas Fields, Tulsa, Oklahoma, USA, 1990.

[7] Pruess K, Oldenburg C, Moridis G. TOUGH2 User's Guide Version 2.0, Lawrence Berkeley National Laboratory Report LBNL-43134, Nov. 1999.

[8] Magoon LB, Valin ZC. Sacramento Basin Province (009), in 1995 National Assessment of United States Oil and Gas Resources: Results, Methodology, and Supporting Data, Digital Data Series (DDS) 30, U.S. Geological Survey, Denver, CO, 1995.

[9] Oldenburg CM. Carbon dioxide as cushion gas for natural gas storage, Energy \& Fuels 2003;17(1):240-246. 


\section{Tables}

\section{TABLE 1}

PROPERTIES OF THE THREE-DIMENSIONAL QUARTER FIVE-SPOT DOMAIN

\begin{tabular}{lcc}
\hline \multicolumn{1}{c}{ Property } & Value \\
\hline Quarter five spot size & $800 \mathrm{~m} \mathrm{x} 800 \mathrm{~m}$ & 160 acres \\
Reservoir thickness & $50 \mathrm{~m}$ & $160 \mathrm{feet}$ \\
Porosity & 0.30 & 0.30 \\
Permeability (isotropic) & $1 \times 10^{-12} \mathrm{~m}^{2}$ & 1 darcy \\
Residual liquid saturation & \multicolumn{2}{c}{0.20} \\
Relative permeability & \multicolumn{2}{c}{ Immobile } \\
Liquid & \multicolumn{2}{c}{ Equal to gas saturation. } \\
Gas & $1.0 \times 10^{-5} \mathrm{~m}^{2} \mathrm{~s}^{-1}, 1.0 \times 10^{-10} \mathrm{~m}^{2} \mathrm{~s}^{-1}$ \\
Molecular diffusivity in gas and liquid & $75 \mathrm{C}$ & $167 \mathrm{~F}$ \\
Reservoir temperature & $50 \mathrm{bars}^{-1}$ & $725 \mathrm{psi}$ \\
Reservoir pressure at start of CSEGR & $3 \mathrm{~kg} \mathrm{~s}^{-1}$ & $260 \mathrm{t} / \mathrm{day}$ \\
$\mathrm{CO}_{2}$ injection rate (per full well) & $0.56 \mathrm{~kg} \mathrm{~s}^{-1}$ & $48 \mathrm{t} / \mathrm{day}$ \\
$\mathrm{CH}_{4}$ production rate (per full well) & $60 \mathrm{bars}^{2}$ & $870 \mathrm{psi}$ \\
Final reservoir pressure (after 15 years) & & \\
\hline
\end{tabular}




\section{TABLE 2}

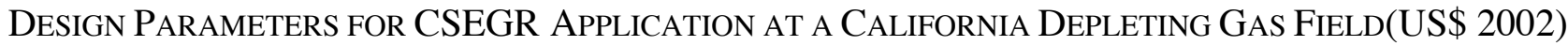

\begin{tabular}{|c|c|}
\hline Parameter & Value \\
\hline Reservoir Depth & 4,921 feet \\
\hline Reservoir Type & Sandstone, High Porosity \& Permeability \\
\hline Total Field $\mathrm{CO}_{2}$ Storage Capacity & $3.6 \times 10^{7} \mathrm{t} \quad 0.7 \mathrm{Tcf}$ \\
\hline Total Field $\mathrm{CO}_{2}$ Injection Rate & $125 \mathrm{MMcfd}$ \\
\hline $\mathrm{CO}_{2}$ Injection Rate (per well) & 5.0 MMcfd \\
\hline $\mathrm{CH}_{4}$ Prod. Rate (Peak per well) & 2.5 to $5.0 \mathrm{MMcfd}$ \\
\hline Wellhead Natural Gas Price & $\$ 3.00$ to $\$ 5.00 / \mathrm{Mcf}$ \\
\hline $\mathrm{CO}_{2}$ Injection Wells & 25 wells \\
\hline $\mathrm{CH}_{4}$ Production Wells & 16 wells \\
\hline Monitoring Wells & 8 wells \\
\hline Project Duration & 15 years \\
\hline \multirow{3}{*}{ Nominal $\mathrm{CO}_{2}$ Content at Production Wells } & Years 1-5: 0\% \\
\hline & Years 5-10: $5 \%$ \\
\hline & Years $10-15: 25 \%$ \\
\hline
\end{tabular}

$\mathrm{Mcf}=1 \times 10^{3} \mathrm{ft}^{3}=28.3 \mathrm{~m}^{3} . \quad$ MMcf $=1 \times 10^{6} \mathrm{ft}^{3} . \quad T c f=1 \times 10^{12} \mathrm{ft}^{3} . \quad \mathrm{t}=$ tonne $=1 \times 10^{3} \mathrm{~kg}$. 


\section{TABLE 3}

Capital Costs (US\$ 2002) For CSEGR Application at a California DePleting Gas Field

\begin{tabular}{lccc}
\hline \multicolumn{1}{c}{ Cost Item } & $\begin{array}{c}\text { Unit Cost } \\
(\mathbf{x ~ 1 0 0 0 ~ U S \$ )}\end{array}$ & Units & $\begin{array}{c}\text { Total Cost (million } \\
\text { US\$) }\end{array}$ \\
\hline Wells & & & \\
\hline $\mathrm{CH}_{4}$ Production Well: New Completion & $\$ 390$ & 4 & 1.56 \\
$\mathrm{CH}_{4}$ Production Well: Workovers & $\$ 40$ & 12 & 0.48 \\
$\mathrm{CO}_{2}$ Injection Well: New Completion & $\$ 460$ & 5 & 2.30 \\
$\mathrm{CO}_{2}$ Injection Well: Converted $\mathrm{CH}_{4}$ Well & $\$ 180$ & 20 & 3.60 \\
Monitoring Well: Converted $\mathrm{CH}_{4}$ Well & $\$ 70$ & 8 & 0.56 \\
Total Well Costs & & & $\mathbf{8 . 5 0}$ \\
Pipelines & $\$ 125$ & $50 \mathrm{~km}$ & 6.25 \\
$\mathrm{CO}_{2}$ Transport Pipeline (8-Inch Diameter) & $\$ 30$ & $10 \mathrm{~km}$ & 0.30 \\
$\mathrm{CO}_{2}$ Field Distribution Lines (2-Inch Diam) & & & $\underline{\mathbf{6 . 5 5}}$ \\
Total CO & & $\mathbf{1 5 . 0 5}$ \\
\hline Total Capital Costs & & & \\
\hline
\end{tabular}


Figure captions.

Figure 1. Schematic of CSEGR processes.

Figure 2. (a) Schematic of well pattern for CSEGR with well spacing of one mile $(1.61 \mathrm{~km})$. (b) Perspective view of quarter five-spot simulation domain.

Figure 3. (a) $\mathrm{CO}_{2}$ mass fraction in the gas and (b) gas density after 15 years of injection into the lower part of the reservoir.

Figure 4. Results of sensitivity analysis showing actual breakeven $\mathrm{CO}_{2}$ supply costs (no subsidy) for various $\mathrm{CH}_{4}$ prices. 


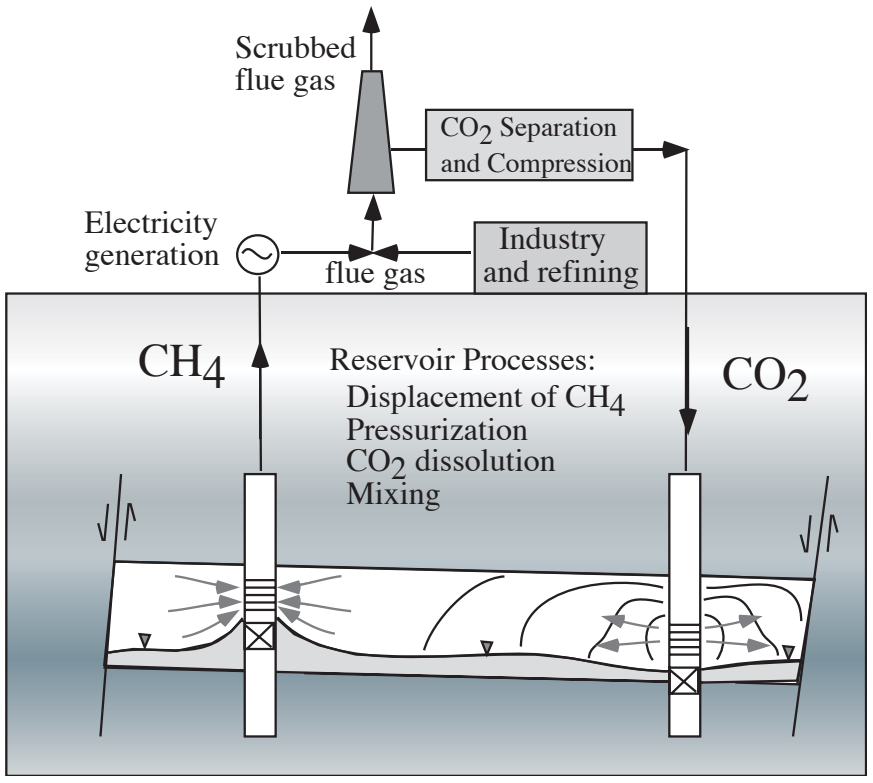

Figure 1. Schematic of CSEGR processes. 


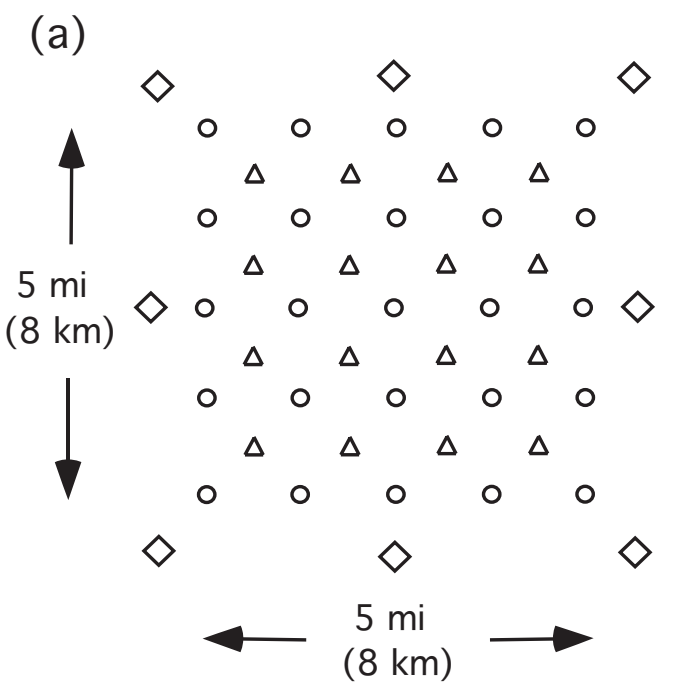

(b)

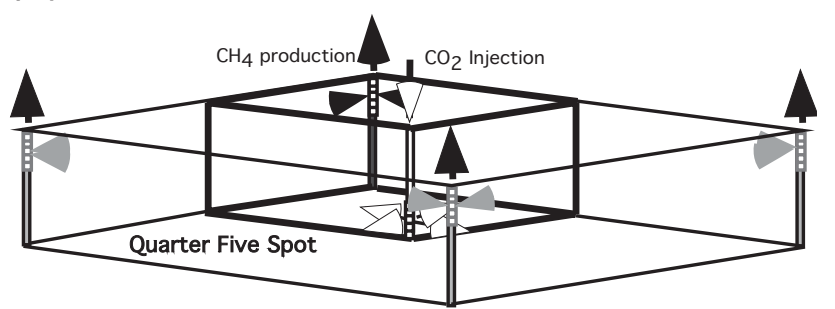

$\Delta \mathrm{CH}_{4}$ Production Well

- $\mathrm{CO}_{2}$ Injection Well

$\diamond$ Monitoring Well

Figure 2. (a) Schematic of well pattern for CSEGR with well spacing of one mile $(1.61 \mathrm{~km})$. (b)

Perspective view of quarter five-spot simulation domain. 

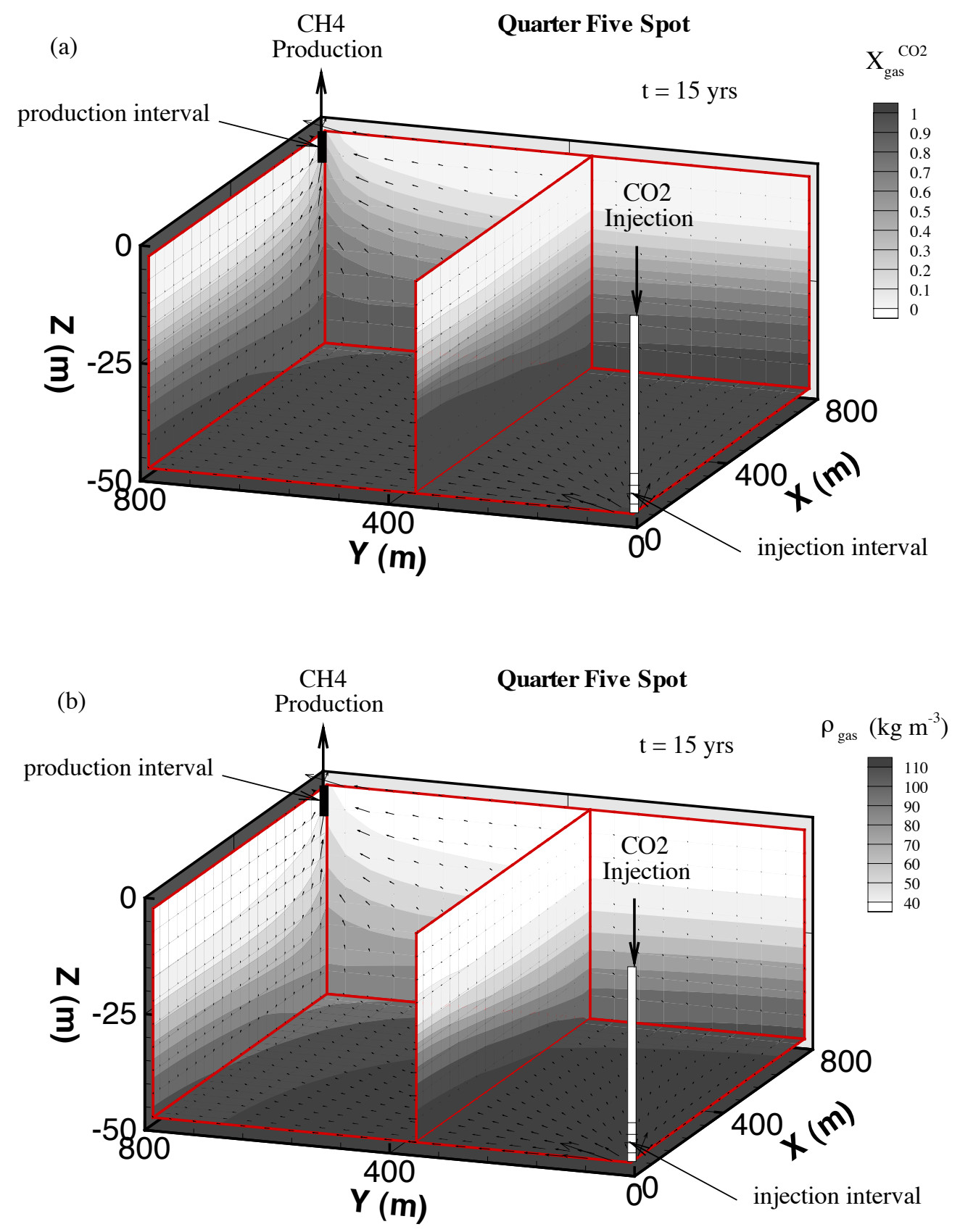

Figure 3. (a) $\mathrm{CO}_{2}$ mass fraction in the gas and (b) gas density after 15 years of injection into the lower part of the reservoir. 


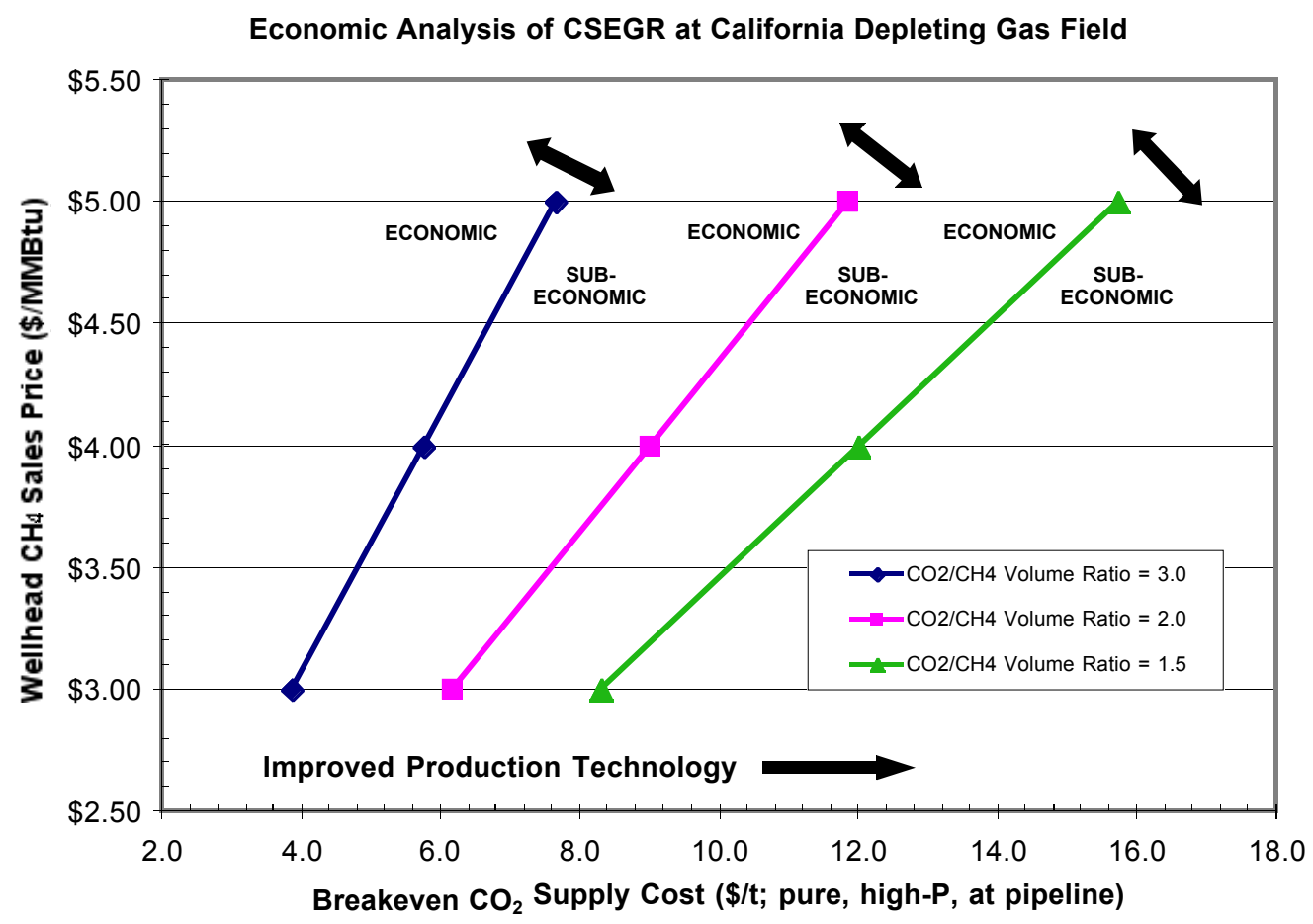

Figure 4. Results of sensitivity analysis showing actual breakeven $\mathrm{CO}_{2}$ supply costs (no subsidy) for various $\mathrm{CH}_{4}$ prices. 